\title{
CAN NUCLEAR POWER SOLVE THE GLOBAL WARMING PROBLEM?
}

\author{
by
}

Ujjayant Chakravorty $^{1}$, Bertrand Magné ${ }^{2}$ and Michel Moreaux ${ }^{3}$

\begin{abstract}
Can nuclear power, which is carbon free, solve the global warming problem? It is a tough sell in the advanced countries, but many new nuclear power plants are under construction in the developing world. We develop an empirical Hotelling model that accounts for the limited stock of uranium, future efficiency improvements in nuclear technology and recycling of nuclear waste. We show that currently known stocks of uranium may be exhausted in a few decades. But advanced nuclear technology can provide clean energy for a longer time. The scarcity of uranium makes nuclear power costly in the future with modest technological change in fossil fuels and solar energy. Because of price-induced substitution, the current price of carbon under a Kyototype climate agreement may be much lower than what is generally expected.
\end{abstract}

Keywords: Clean Energy, Dynamic Models, Energy Resources, Hotelling Theory, Resource Substitution

JEL codes: Q32, Q41, Q48

\footnotetext{
${ }^{1}$ Department of Economics, University of Central Florida, Orlando, FL, 32816-1400.

${ }^{2}$ University of Toulouse (CEA, LERNA), 21 allée de Brienne, 31000 Toulouse.

${ }^{3}$ Corresponding Author: University of Toulouse (IUF, IDEI and LERNA), 21 allée de Brienne, 31000 Toulouse, phone 33(0) 561 128523, mmoreaux@cict.fr.
} 


\section{Introduction}

The recent ratification of the Kyoto Protocol into a binding international treaty has revived interest in clean energy alternatives. The Protocol limits the global emission of carbon to a level 5\% below 1990 levels. ${ }^{4}$ Carbon-emitting fossil fuels such as coal, oil and natural gas currently account for nearly $85 \%$ of global energy consumption. Limiting carbon emissions is expected to result in a significant cost to the global economy because countries must depend less on fossil fuels and switch to carbon free fuels. While much attention has focused on the economic mechanisms for achieving carbon reductions, there has been little economic research on what may be the long-run alternatives to a dependence on fossil fuels, especially coal.

If coal use has to be curtailed, a major substitute must be found for power generation. Natural gas is a cleaner option, but it is available in limited quantities. Hydropower is carbon free and economical, but large scale deployment of hydroelectric dams on rivers is politically infeasible, given their adverse impacts on the local environment. Other substitutes such as renewable energies (solar and wind power) are frequently proposed as alternatives, but cannot supply the large volumes of energy needed for base-load power generation.

In this paper, we model an energy option that is controversial, especially in the developed countries, but has been a major contributor in reducing the extent of global warming and air pollution. Nuclear power accounts for $20 \%$ of all electricity generated in the U.S. and a sixth of all electricity production globally. Seventeen countries depend on it for at least a quarter of their electricity (World Nuclear Association, 2003). Global nuclear generation capacity exhibited

\footnotetext{
${ }^{4}$ In fact, global carbon emissions are up by more than 10 percent since 1990, the benchmark year for the Protocol (IEA, 2001). Even if the Kyoto agreement fails, it is expected that any modified agreement must cap the stock of carbon.
} 
double digit growth until 2000, and continues to grow rapidly in the developing countries. More than 30 new reactors are under construction. In the U.S., nuclear power has been used to replace coal to meet the requirements of the Clean Air Act, especially in the northeast. ${ }^{5}$

We ask whether nuclear power could serve as a source of clean energy. How would the current expansion of nuclear power affect the price of uranium, and the price of carbon? How will it affect the long-term use of fossil fuels as well as the production of nuclear wastes over time? What role would nuclear power play if global energy demand were increasing and possibly levelling off in the long run as population and energy consumption levels become stable? We model two nuclear technologies, traditional nuclear power which produces a higher volume of radioactive wastes, and a modern technology (prototypes of which are already operational), that re-uses a significant portion of wastes.

The economic modeling of nuclear power presents several methodological challenges. First, since major energy resources are nonrenewable, we use a Hotelling framework in which prices reflect the scarcity of the resource. Second, carbon emission caps like those proposed by the Kyoto Protocol are imposed in the form of a ceiling on the stock of pollution. Third, nuclear power is strictly neither a nonrenewable nor a renewable resource. Its major raw material, uranium is a nonrenewable resource, but the output (reprocessed uranium and plutonium) can be re-used as input. We need to consider recycling of the nonrenewable resource.

\footnotetext{
5 "Most of the avoided carbon dioxide emissions over the last 20 years have come from nuclear power," according to a U.S. Department of Energy official (Moniz, 1999). In his 2005 State of the Union address, U.S. President George W. Bush called for an expansion of "safe, clean" nuclear energy.
} 
There are few studies of the long-run economics of nuclear energy. Cropper (1980) has examined a theoretical model of the trade-offs between fossil fuels and nuclear energy. Most empirical studies on energy tend to use sophisticated general equilibrium models. ${ }^{6}$ Substitution between resources is imposed exogenously and not based on scarcity-induced prices. Nordhaus (1979) pioneered this endogenous substitution approach to examine the impact of OPEC-induced oil price shocks on the U.S. economy and subsequently Chakravorty et al. (1997) modeled cost reductions in solar energy due to exogenous research and development.

We first propose a simple theoretical model that extends the standard Hotelling framework to include a ceiling on the stock of pollution. This model is then extended empirically to examine the substitution among multiple nonrenewable resources and nuclear power. The results suggest that when the stock of carbon emissions is capped, nuclear power immediately becomes cheaper than coal in the generation of electric power. However, even a modest expansion of nuclear power at lower than historical rates results in the exhaustion of all known reserves of uranium in a few decades. The Hotelling rent for uranium is significant, suggesting that unless major new reserves of uranium are discovered, nuclear power may not emerge as a long-run alternative to coal, which is available in abundance. Nuclear power supplies energy for a significantly longer period when more efficient nuclear technology is used. Oil and natural gas are still exhausted, but less coal is used.

Nuclear power becomes less important however, when the cost of fossil fuels and solar power decline over time due to technological change. Then it mainly serves as a transition from fossil

${ }^{6}$ e.g., see Manne and Richels (2002), and other studies published in a special issue of the Energy Journal (1999), The Costs of The Kyoto Protocol: A Multi-Model Evaluation. 
fuels to clean renewable energy. With technological change, the scarcity rent of uranium falls almost 100 fold.

The model shows the effects of price-induced resource substitution in future periods on the current price of carbon. Most estimates suggest a range of $\$ 20$ to $\$ 100 /$ ton of carbon. In our case, the imputed price of carbon is found to be quite sensitive to assumptions regarding long-run technological change. With conventional nuclear power, the current price of carbon is $\$ 40 /$ ton, which decreases sharply to $\$ 10 /$ ton with modest reductions in the cost of solar energy and fossil fuels. These estimates are significantly lower than conventional estimates that do not allow for endogenous substitution. They suggest that implementation of an agreement such as the Kyoto Protocol may not result in high carbon prices when substitution effects are taken into account.

Section 2 introduces a simple Hotelling model with a cap on the stock of emissions. Section 3 develops the empirical model and discusses the model results. Section 4 concludes the paper.

\section{A Dynamic Model with a Cap on the Stock of Emissions}

In this section we develop a Hotelling model with a carbon ceiling. We assume one demand, one polluting nonrenewable resource and a "clean" backstop resource. The theoretical model is presented mainly to develop insights on the effects of an emissions ceiling on the standard Hotelling framework. The main conclusion here is that because of a ceiling on the stock of emissions, we may observe the joint use of a polluting nonrenewable resource and a clean renewable before a complete transition to the latter. 
Let the instantaneous utility at time $t$ generated by energy consumption $q(t)$ be given by $u(q(t))$ which is assumed to be strictly increasing and concave in $q$, i.e., $u^{\prime}(q)>0, u^{\prime \prime}(q)<0$. Energy is produced by two resources - a polluting fossil fuel (e.g., coal) and a non-polluting renewable (e.g., nuclear power). ${ }^{7}$ These resources are perfect substitutes. Their consumption rates are given by $x(t)$ and $y(t)$ respectively. Utility from energy consumption is thus given by $u(x(t)+y(t))$.

The initial reserves of the nonrenewable resource are assumed known, denoted by $X(0)$. Let the unit extraction cost, i.e., inclusive of processing and transportation be $c_{e}$. Define the pollution per unit of the resource to be $\zeta$. This may be the amount of carbon generated per unit of coal used.

Then $X(t)$ is the residual nonrenewable resource available at time $t$, where $\dot{X}(t)=-x(t)$.

Let $x_{c}$ be the consumption level for which the marginal utility is equal to the unit cost of the resource, i.e., $u^{\prime}\left(x_{c}\right)=c_{e}$. Denote $Z(t)$ to be the stock of pollution at time $t$, and $Z(0)$ the initial stock. Pollution from use of the nonrenewable resource increases $Z(t)$, but a portion declines naturally at an assumed rate $\alpha>0$. That is, the growth of the pollution stock is given by $\dot{Z}(t)=\zeta x(t)-\alpha Z(t)$. Define the ceiling on the stock of carbon to be $\bar{Z}$ with $Z(0)<\bar{Z}$. We assume that this ceiling cannot be exceeded. Let $\bar{x}$ be the maximum consumption rate of the nonrenewable resource if $Z(t)$ equals its ceiling $\bar{Z}$, i.e., $\bar{x}=\alpha \bar{Z} / \zeta$, and $\bar{p}_{e}$ the corresponding marginal utility, so that $\bar{p}_{e}=u^{\prime}(\bar{x})$.

\footnotetext{
${ }^{7}$ We treat nuclear power as a renewable resource and abstract from considering details of the technology such as recycling of output (plutonium) back into production which are considered in the empirical model.
} 
Finally, let $c_{r}$ be the constant unit cost of the renewable resource. This cost is higher than the cost of the nonrenewable resource, $c_{r}>c_{e}$. We further assume that the renewable resource is abundant, and $y_{c}$ (analogous to $x_{c}$ ) is the consumption level for which the marginal utility equals the unit cost of the renewable resource, i.e., $u^{\prime}\left(y_{c}\right)=c_{r}$. The social planner chooses extraction rates of the two resources to maximize welfare under the pollution stock constraint as follows:

$\max _{\{(x(t), y(t)\}} \int_{0}^{\infty}\left\{u(x(t)+y(t))-x(t)-c_{r} y(t)\right\} e^{-\rho t} d t$

subject to the two differential equations in $\dot{X}(t)$ and $\dot{Z}(t)$, and given values of $X(0), Z(0)$ and $\bar{Z}$. The current value Lagrangian is

$L(t)=u(x(t)+y(t))-c_{e} x(t)-c_{r} y(t)-\lambda(t) x(t)+\mu(t)[\zeta x(t)-\alpha Z(t)]$.

The first order conditions are

$u^{\prime}(x(t)+y(t))-c_{e}-\lambda(t)+\zeta \mu(t) \geq 0 \quad(=$ if $x(t)>0)$, and

$u^{\prime}(x(t)+y(t))-c_{r} \geq 0 \quad(=$ if $y(t)>0)$.

The dynamics of the system is determined by

$\dot{\lambda}(t)=\rho \lambda(t) \Rightarrow \lambda(t)=\lambda(0) e^{\rho t}$, and

$\dot{\mu}(t)=(\rho+\alpha) \mu(t)+v(t), \quad v(t) \geq 0$,

with $v(t)[\bar{Z}-Z(t)]=0$. Here $\lambda(t)$ is the shadow price of the nonrenewable resource and $\mu(t)$, which is non-positive, is the shadow price of a unit of emission. Lastly, the transversality 
conditions at infinity are $\lim _{t \uparrow+\infty} e^{-\rho t} \lambda(t) X(t)=\lambda(0) \lim _{t \uparrow+\infty} X(t)=0$, and $\lim _{t \uparrow+\infty} e^{-\rho t} \mu(t) Z(t)=0$.

While the purpose of this paper is not to characterize the complete solution to the above problem, we can provide an interpretation of the necessary conditions. Condition (2) equates the marginal benefit of an additional unit of the polluting nonrenewable resource to its total marginal cost, which includes the unit cost of extraction $c_{e}$, the scarcity rent $\lambda(t)$, and the externality cost $-\zeta \mu(t)$. Equation (3) equates the marginal benefit from the renewable resource with its unit extraction $\operatorname{cost} c_{r}$. Condition (4) gives the standard Hotelling relationship that scarcity rent $\lambda(t)$ must rise at the rate of interest (Hotelling, 1931). The shadow price of externality $\mu(t)$ which is negative, must increase at a rate equal to the sum of the discount rate and the natural decay rate of pollution except when the ceiling is binding, in which case the value of the constraint $v(t)$ is non-zero. Finally the transversality conditions suggest that at the end of the planning horizon, the value of the nonrenewable resource stock must go to zero, the stock must be exhausted and the value of the pollution stock must also go to zero.

One possible solution to the above problem which is consistent with the empirical results below is shown in Fig. 1. The curve $M C_{A}$ represents the unit extraction cost plus the shadow price of the nonrenewable resource over time if there was no ceiling constraint. This is the familiar Hotelling model with no pollution. The nonrenewable resource is consumed from the beginning until time $\theta$, when it is exhausted and the renewable resource is used at the constant consumption rate $y_{c}$. The curve $M C_{B}$ represents the marginal cost of the nonrenewable resource with the ceiling constraint, and includes the extraction cost, the shadow price of the nonrenewable resource and 
the shadow price of pollution. $M C_{B}$ increases to equal the cost of the renewable resource $c_{r}$ at time $t_{1}$. The stock of pollution also increases during this time period, and hits the ceiling exactly at $t_{1}$. However, at price $c_{r}$, demand is too high to be satisfied purely by the nonrenewable resource without violating the ceiling, hence some clean renewable resource is also used. From $t_{1}$ to $t_{2}$ the pollution level is at its maximum and the ceiling is binding. The extraction rate for the nonrenewable resource at the ceiling is the maximal rate $\bar{x}$, and the marginal cost of the nonrenewable resource, $M C_{B}$ is exactly equal to the marginal cost of the renewable resource, $c_{r}$. The addition to the stock of pollution exactly equals the natural decay, $\zeta \bar{x}=\alpha \bar{Z}$. The nonrenewable resource gets exhausted at time $t_{2}$ and the renewable resource becomes the sole supplier of energy. The ceiling is no longer binding from time $t_{2}$, and the stock of pollution declines gradually to zero. Hence from time $t_{2}$ the shadow price of pollution is zero, so that $M C_{B}$ is just equal to the extraction cost plus the shadow price of the nonrenewable resource, and is higher than $c_{r}$. Hotelling scarcity rents in the model with the pollution limit, depicted by the curve $M C_{C}$, are lower than in the unconstrained case, $M C_{A}$.

The corresponding equilibrium quantities are shown in the lower graph of Fig. 1. The dashed curve corresponds to the pure Hotelling path, without the ceiling constraint. Nonrenewable resource extraction declines to $y_{c}$ at time $\theta$, followed by use of the renewable resource. The solid lines show the case with the ceiling constraint. Here nonrenewable resource use declines to $y_{c}$ at time $t_{1}$, and stays at level $\bar{x}$ (less than $y_{c}$ ) from time $t_{1}$ to $t_{2}$ until exhaustion. The renewable resource is used beginning time $t_{1}$ at level $y_{c}-\bar{x}$ until time $t_{2}$, and at level $y_{c}$ upon exhaustion 
of the nonrenewable resource. Note that $t_{1}<\theta<t_{2}$. Introducing a pollution constraint initially slows down the extraction rate of the nonrenewable resource until $\theta$, but extends the time period during which the polluting nonrenewable resource is used, the cumulative demand being the same in both cases and equal to the initial stock.

There may be several other solutions depending on the values of the exogenous variables. For example, the maximal pollution rate at the ceiling $\bar{x}$ may be larger than $y_{c}$, in which case only the nonrenewable resource will be extracted at the ceiling followed by a Hotelling-type transition to the renewable resource. Other patterns may arise depending upon the relative magnitudes of $\bar{x}$ and $y_{c} \cdot{ }^{8}$

\section{The Empirical Model with Fossil Fuels and Nuclear Power}

The empirical model has several demands and nonrenewable resources, a model of the nuclear technology with recycling of materials and a backstop renewable resource (solar power). We focus on the main economic features of the model and provide the details of the nuclear technology in Appendix A. There are four sectors in this energy economy - specific electricity, transportation, residential and commercial, and industrial. As in Nordhaus (1973), they are characterized by independent demands that are a function of energy prices and income.

Generalized Cobb-Douglas demand functions for each sector are given as $D_{j}=A_{j} P_{j}^{\alpha_{j}} Y^{\beta_{j}}$, where $\alpha_{j}$ and $\beta_{j}$ are respectively the price and income elasticities for demand in sector $j, A_{j}$ is the sector-specific technical coefficient, $P_{j}$ is the price of delivered energy in sector $j$, and $Y$ is

\footnotetext{
${ }^{8}$ See Chakravorty et al. (2003) for a complete analytical solution.
} 
global GDP which is expected to increase exogenously over time, but at a declining rate. We consider the three major fossil fuels - oil, natural gas and coal. In order to approximate reserves with different extraction costs, we consider two grades each of oil and natural gas (as in Nakicenovic and Riahi, 2001), and because coal is much more abundant, three grades of coal, each with constant extraction cost. The data used in the model is detailed in Appendix B.

We maximize consumer plus producer surplus subject to the technological relationships and stock dynamics. The main innovation is the embedding of the nuclear technology with recycling of materials in a Hotelling model. The nuclear technology is optimized by choosing the amount of energy produced by the two technologies, Light Water Reactor (LWR) and Fast Breeder Reactor (FBR) (see Appendix A). ${ }^{9}$ Here we only provide an intuitive discussion of the optimization problem and describe how it is integrated into the general model along with the other energy sources, namely oil, coal, natural gas and solar energy.

The stocks of oil, coal, natural gas and uranium are all finite. Thus each of them has a Hotelling scarcity rent. The combustion of fossil fuels releases carbon into the atmosphere. Nuclear power is carbon free. Conventional LWR technology uses uranium ore as input. Modern FBR technology uses a mix of several inputs, including wastes from LWR production. The algorithm chooses the least cost energy supply for each sector. The two nuclear technologies may be deployed jointly. Unlike for fossil fuels, production of nuclear power creates the need for reprocessing and storage of wastes. Their disposal is costly and must be included in the total

\footnotetext{
${ }^{9}$ The LWR is the standard nuclear technology currently used in most countries. It uses uranium and produces a relatively large volume of waste. The FBR is a modern technology with higher capital costs, prototypes of which are available. It uses uranium and plutonium and recycles a larger portion of the waste.
} 
marginal cost of nuclear energy. In models where only traditional LWR technology is available, these wastes do not have economic value so their shadow price is zero. However, when modern FBR technology is also an option, wastes have economic value as inputs in FBR operation, so they have a non-zero scarcity rent. Solar energy is a backstop resource, producing electricity at constant unit cost. We run several scenarios, described as follows:

\begin{abstract}
A. The Baseline Model: Fossil Fuels without a Cap on Emissions: This model is run with estimated stocks of fossil fuels - oil, coal and natural gas, and solar energy as the backstop. It has no nuclear power and no cap on carbon emissions. ${ }^{10}$
\end{abstract}

\title{
B. The Business-As-Usual (BAU) Model: An Emissions Cap with Traditional Nuclear Technology
}

This scenario imposes a clean carbon target with conservative assumptions on the growth of nuclear power. We only consider traditional nuclear technology. This may be representative of a situation in which there are no major technological improvements in the production of nuclear power. Even if the social and political problems relating to nuclear energy were to be resolved, it is unrealistic to expect an instantaneous expansion of nuclear capacity given the long lead times (about 7-10 years) involved in licensing, constructing and commissioning of nuclear power plants. So we exogenously impose an upper bound on the growth rate of nuclear capacity in the model equal to a $1.6 \%$ annual increase (OECD, 2000a). ${ }^{11}$ The cap on the stock of emissions is set at $550 \mathrm{ppm}^{12}$

\footnotetext{
${ }^{10}$ This is the Chakravorty et al. (1997) model with updated energy data. We have ignored the contribution of existing nuclear capacity in running this polar case, as well as other resources such as hydroelectricity and biomass, all of which together account for about $15 \%$ of current supply.

${ }^{11}$ This is a conservative estimate. For example, nuclear energy production has grown by a factor of 12 between 1973 and 2000, which is equivalent to an annual average increase of about 12\% (IEA, 2001).

${ }^{12} \mathrm{~A} 550 \mathrm{ppm}$ carbon cap is applied in all the models, except model $\mathrm{F}$, which examines the sensitivity to
} 


\section{The Pro-Nuclear Model: An Emissions Cap with both Traditional and Modern Nuclear} Technologies: Nuclear production capacity is assumed to increase faster when both nuclear technologies are available. When FBR technology is an option, we again impose a maximum $1.6 \%$ annual rate of increase (same as in model B) in nuclear generation until 2020 then double this expansion rate for future periods. This model captures a pro-nuclear policy environment, with availability of breeder technology and a faster growth in generation capacity in the future.

\section{The Pro-Nuclear Model plus Technological Change in Fossil Fuels and Solar Energy:}

Technical change in the energy sector is modelled through exogenous reductions in costs. Since investment and operating costs are significant in the nuclear industry (ranging from 60 to $80 \%$, depending on the discount rate used for calculations), we apply a cost reduction of $4.4 \%$ per decade, the rate chosen such that the unit cost of FBR technology decreases to the level of LWR technology in about 50 years. ${ }^{13}$ The cost of LWR technology is assumed constant. It is likely that this technology has achieved maturity and future learning-by-doing effects may be relatively small. Any cost reductions may be compensated by increased safety and proliferation measures which must be part of any major nuclear expansion program (MIT, 2003). The cost of electricity from solar power is assumed to decrease at a rate of $20 \%$ per decade. ${ }^{14}$ We assume that fossil fuel conversion costs are reduced by $1 \%$ every five years, which leads to approximately constant enduser energy prices during this century, with cost reductions offsetting the increase in scarcity

\footnotetext{
alternative carbon targets.

${ }^{13}$ Ex ante, it is hard to predict the learning by doing and other benefits of FBR adoption. However, they are expected to be significant, as suggested by several studies (e.g., MIT, 2003). We apply a conservative estimate.

${ }^{14}$ This figure is an approximation of the slope of the learning curve for photovoltaic electricity (OECD, 2000b).
} 
rent. ${ }^{15}$ Extraction costs of fossil fuels are maintained at previous levels.

E. The Pro-Nuclear Model with a Levelling off in the Demand for Energy: While the previous cases examined the near term scenario of increasing demand, recent empirical evidence suggests that global fertility rates and population have begin to decline in many countries that have historically exhibited high rates of growth (Lutz, Sanderson and Scherbov, 2001). ${ }^{16}$ With the general aging of these societies, energy demand will likely follow this declining trend, albeit with a time lag that accounts for the inevitable increase in energy consumption per capita for residents of developing countries. We use these population and GDP per capita assumptions to consider the long-run case when demand for energy stabilizes with time. In all the other models, we assume a steady decline in GDP growth over time. However, for model E, we consider an increase in the GDP growth rate in the near term followed by a decline, which reflects more accurately the expected sharp decline in population and levelling of per capita energy use in the long run. In this run, both nuclear technologies are available and there is no technical progress.

F. Sensitivity Analysis with Alternative Emission Caps: We examine the sensitivity of resource use, emissions and the shadow price of carbon to alternate carbon targets (450-650 ppm).

Table 1 shows the time profile of energy substitution in the baseline case (model A) with time

\footnotetext{
${ }^{15}$ In general, fuel prices have been constant because of technical progress (Parry, 1997). Ignoring market incentives for fossil fuel cost reduction may result in underestimating extraction and emission rates. An important advantage of this assumption of approximately constant resource prices is that it responds to critics of the Hotelling theory, who argue that historically, long-run resource prices have not exhibited scarcity effects and models that rely on Hotelling-induced resource price movements may be misspecified.

${ }^{16}$ According to Lutz et al., world population is expected to rise from its present level of 6 billion to about 9 billion in 2070 , then drop to 8.4 billion in 2100 . Fertility rates have fallen below replacement levels in many developed and developing countries. Other UN predictions suggest that the population peak may occur sooner, reaching 7.4 billion in 2045 before starting a decline (United Nations, 2002).
} 
intervals marked in decades. Coal is used in electricity generation, oil in transportation and natural gas in residential and industrial sectors. Both oil and gas get exhausted ultimately and are replaced by coal. Coal reserves are much larger than that of the other two fossil fuels, leading to a relatively low scarcity rent for coal. Finally all sectors transition to the backstop resource, solar energy. Table 2 shows the share of each fuel by sector at various dates. Natural gas supplies the bulk of energy consumption during the next 50 years and declines subsequently while the share of coal increases to make up the deficit. The general shift from coal to natural gas in electricity generation in recent years supports this conclusion. The ultimate heavy dependence on coal in this nuclear free scenario also raises carbon emissions. The carbon concentration (shown in Fig. 2) reaches a level of $750 \mathrm{ppm}$ in the year 2100 and a maximum level of about $1620 \mathrm{ppm}$ in 2260 , which is generally believed to be in the range that may cause catastrophic damages (Alley et al., 2003). Emissions reach a maximum of 43 billion tons in $2180 .{ }^{17}$

We next impose a carbon cap and consider the use of nuclear power (Table 3). Table 3(a) shows resource use when only conventional nuclear power (LWR) is available (model B), and Table 3(b) shows both technologies (LWR and FBR, model C). Consider only the LWR option first. A cap on the stock of emissions raises the cost of fuels emitting carbon. The cost of coal, oil and gas rise, in decreasing order due to their respective pollution contents. Nuclear power becomes immediately economical in electricity generation and is used at maximum capacity, jointly with coal until uranium is exhausted (by 2100). Solar becomes competitive upon depletion of uranium, since the high shadow price of carbon makes coal too expensive. Compared to the model without a carbon cap, the cost of coal in electricity increases from 5 to 6.5 cents per $\mathrm{kWh}$ for the start year

\footnotetext{
${ }^{17}$ This is more than a five fold increase from current annual emissions of about 7.35 billion tons.
} 
2000. ${ }^{18}$ Coal continues to substitute when both oil and gas resources run out, except in transportation where solar has an advantage relative to coal, as shown in the table. Oil and gas retain their comparative advantage in the other sectors as before. The carbon ceiling is reached in about 100 years (see Fig. 2). Uranium is a scarce resource, and its scarcity rent is a high $\$ 1,542 / \mathrm{kg}$ (see Table 4). ${ }^{19}$ Nuclear power is not a long run alternative in this case, since uranium is exhausted within this century, even with a phased expansion of nuclear capacity. Coal and solar power dominate when oil and gas are depleted. $^{20}$

With the availability of the new nuclear technology (FBR) in model $\mathrm{C}$, it becomes economical in electricity generation in the year 2075 (see Table 3(b)). Because of the higher fuel efficiency of FBR, nuclear power ultimately supplies energy in all sectors and its share rises over time (see Table 2). Some coal is used jointly with nuclear in the transportation sector once oil is exhausted. However, only $16.3 \%$ of aggregate coal is used in this scenario, and the scarcity rent for coal is zero. The available reserves of oil and natural gas however, continue to be exhausted and their respective comparative advantage in transportation and the residential and industrial sectors seem unaffected by the availability of modern nuclear technology.

With both nuclear options, LWR technology is abandoned around the middle of the next century

\footnotetext{
${ }^{18}$ With a carbon cap but without nuclear power, the high price of carbon prevents coal from being used for electricity production in the initial period. The electricity sector is supplied by oil for the next 30 years. Solar becomes competitive early in this sector, in the year 2090. These results are not shown in the paper. ${ }^{19}$ Some studies (e.g., MIT, 2003) have suggested that the price of uranium is a small fraction of the total cost of nuclear power. Our analysis, which treats uranium as a finite resource, indicates that even if the cost of uranium is small, its scarcity rent is likely to be quite high. A high shadow price of uranium, however, will trigger new discoveries of the resource, and augmentation of the initial stock assumed fixed in our case. With these augmented reserves, the shadow price of uranium may be lower but probably still quite significant.

${ }^{20}$ In our model, nuclear capacity is endogenously determined, but these estimates are in the range of engineering feasibility studies (see MIT, 2003) which suggest that an expansion of electricity production from the present 367 billion to 1000 billion watts by 2050 is feasible and given known uranium reserves, this deployment can be maintained for about 40 years.
} 
and FBR supplies all of the nuclear energy (Table 3(b)). When oil and gas reserves get exhausted, nuclear power supplies electricity which is then used in the residential, industrial and transportation sectors. Coal is still used because it is the cheapest among all energy resources. However, because the carbon concentration is at its maximum allowable limit, the quantity of coal that can be used is limited to the amount that compensates for the atmospheric removal of carbon. With modern nuclear technology, solar power is no longer used. The available supply of uranium is enough to generate the plutonium needed to run the FBR facilities. These results represent the "best case" for the expansion of nuclear power.

When costs decline exogenously (model D), nuclear power again becomes less important. Both technologies are used, but solar energy substitutes for nuclear power late this century (see Table 5). Electricity from solar and nuclear power is used in the transportation sector. The residential sector continues to use cheap gas, which along with oil also provides energy for the industrial sector. Exogenous cost reductions make coal relatively costly and only $2.3 \%$ of it is used in the aggregate. The use of lower grades of oil which become cheaper with time is stretched out for a relatively long time. Cost reductions lead to a decline in the shadow price of carbon to $\$ 10 /$ ton of carbon in the year 2000 (see Table 4 and the bottom graph in Fig. 3). The carbon concentration reaches a ceiling at the beginning of the next century, but stays at that level relatively briefly (see Fig. 2). This suggests that modest technical change in other clean fuels (such as solar power) may reduce the role of nuclear power and it may significantly reduce the time during which the ceiling is binding, as seen by comparing the bottom two graphs in Fig. 2 .

The present value (in year 2000) of the scarcity rent of uranium and the imputed price of a ton of 
carbon for the various cases are shown in Table 4. Uranium prices are generally high except in the case with technical change $(\$ 17 / \mathrm{kg})$. They are at their maximal levels when only LWR technology is an option, and remain high even with a doubling of the stock of uranium. They decline significantly when both technologies are available because of the recycling of wastes. The model with standard nuclear technology is driven mainly by coal, since uranium is in short supply. The intense use of coal drives up the price of carbon, so the current price of carbon is $\$ 40 /$ ton and a high $\$ 456 /$ ton in the year 2100 (see Fig. 3). The price of carbon decreases with an increase in the target carbon level and is highly sensitive to it (see Table 4). The corresponding time paths are shown in Fig. 4. It also decreases with availability of modern nuclear technology. This is because FBR technology allows coal to be abandoned at a much earlier time, ceteris paribus. The price path of carbon also grows at a slower rate, as seen from comparing Figs. 3 and 4. The imputed price of carbon is useful in examining the general equilibrium effects of say, carbon taxes or a market in carbon permits. For example, an expansion in the supply of nuclear power will reduce the price of carbon, and lead to lower amounts of carbon sequestration in other sectors such as farming or forestry. It may also mean a smaller domestic and international market for carbon permits.

With stagnation in energy demand (model E), less carbon emitting fuels are used, which decreases the shadow price of carbon (Table 4). The price of carbon in year 2000 decreases from $\$ 26$ to $\$ 22 /$ ton. However, this decline in the price of carbon also makes carbon emitting fuels cheaper, and leads to an increase, albeit small, in energy consumption and emissions. The scarcity rent of uranium falls from $\$ 160$ to $\$ 95 /$ ton (Table 4). The bulk of energy supplies in the future come from nuclear power, which is the more expensive fuel relative to coal given the high 
scarcity rent of uranium. Only $6.5 \%$ of the aggregate coal stock is ultimately extracted in this case. The levelling of energy demand leads to a $35 \%$ reduction in cumulative energy use over the entire time horizon.

One can in general observe a tradeoff between fossil fuels which produce carbon and nuclear power which produces toxic wastes. Waste production is significantly lower under FBR technology, because of reprocessing of uranium and plutonium (Fig. 5). For example, in the year 2100 , cumulative nuclear wastes are 1.57 million tons with traditional nuclear technology and 2.1 million tons in 2130 when nuclear energy is phased out. Only 0.4 million tons of nuclear wastes are produced in 2100 with the new FBR technology, despite a much larger nuclear electricity generation, but some 12.6 million tons will have ultimately accumulated within four centuries, because of widespread adoption of the new technology.

\section{Concluding Remarks}

This paper asks if nuclear power could be an answer to global warming by applying a generalized Hotelling model with price-induced substitution across resources. If the stock of atmospheric carbon is capped under a climate agreement, nuclear power is likely to substitute for coal, especially in power generation. However, the supply of uranium is limited and continued adoption of nuclear power at current rates could only be sustained for a few decades. Currently known stocks of oil and natural gas are always exhausted, since they have significant comparative advantage. With present nuclear technology, limited supplies of uranium may only be enough for use over a short time horizon. Even though the contribution of uranium to total nuclear costs is low, the scarcity rent of uranium increases with significant adoption of nuclear power. In the 
future, uranium producers could engage in cartel-like behavior since the metal is mainly found only in four countries, fewer than for crude oil.

The results show that the non-monotonic behavior of energy demand in the long run may determine whether individual countries may benefit from joining an agreement such as the Kyoto treaty, submit to emission controls and participate in a global carbon market, or grow without any restrictions on carbon emissions but join later in time. A continued expansion of nuclear power and technological change in alternative resources is likely to shrink the market for carbon and reduce carbon prices. Countries outside the treaty with a potential surplus in permits may profit from joining the treaty and selling their permits rather than wait for a seller's market in the future. For the United States, the Kyoto Protocol (especially with its limitations on trading mechanisms) could result in carbon prices that are too high leading to too much sequestration, especially if there was a domestic market for carbon. Credible policy announcements towards expanding nuclear capacity may lead to a downward effect on the price of carbon.

Although we apply a Hotelling model with endogenous substitution among resources, it is clear that a simple application of textbook Hotelling theory (the one-resource one-demand model) is inadequate for making a realistic assessment of the long-run prospects of technologies such as nuclear power. Theoretical extensions of Hotelling that incorporate recycling of resources need to be developed.

A discussion of the economics of nuclear power is timely, since licenses for most of the 103 
plants in the US are up for renewal (for another 20 years). ${ }^{21}$ Given anti-nuclear sentiment, it is likely that there will be a continued moratorium on new nuclear plants in the developed world, although some of these plants may be permitted to increase generation capacity. However at the same time, the number of plants is expected to increase in the developing countries.

As is well known, public opinion especially in the Western countries, is strongly against the proliferation of nuclear power plants. The objections are primarily three fold - waste disposal, reactor meltdowns and the possibility of weapons proliferation. FBR technology partly mitigates the first concern by recycling a much higher proportion of waste by-products, although they also increase risk by requiring more handling. Loss-of-coolant accidents as in Three Mile Island and Chernobyl, can be avoided in the future through "passively safe" reactors that are cooled by helium and lined with graphite pebbles (Hoffert, 2002). Various studies have suggested that the level of exposure for the present generation (over the next 100 years) due to direct radioactive releases from nuclear facilities into the environment is extremely low and that the individual risk can be considered as "negligible" (Nordhaus, 1997). Others (cited by Radetzki, 2000) point out that the external costs of coal (from global warming and air pollution) are much higher than for nuclear (waste treatment and disposal and the low probability event of a catastrophe). However, public perceptions are different, and nuclear power is assumed to be more damaging than coal, in part because of the difficulty of comprehending low probability events (Viscusi, 1992).

\footnotetext{
${ }^{21}$ Thirty of them have received extensions from the Nuclear Regulatory Commission, and another 40 are up for renewal.
} 


\section{References}

Alley, R.B. et al. (2003), Abrupt Climate Change, Science 299 (March), 2005-10.

Brown, C.E. (2002).World Energy Resources. Berlin: Springer-Verlag.

Chakravorty, U., B. Magné and M. Moreaux (2003). A Hotelling Model with a Ceiling on the Stock of Pollution, unpublished manuscript.

Chakravorty, U., J. Roumasset and K-P. Tse (1997), Endogenous Substitution among Energy Resources and Global Warming, Journal of Political Economy, 105, 1201-34.

Charpin, J.M. (2000). Mission d'évaluation économique de la filière nucléaire. Le parc nucléaire actuel \& La prospective technologique de la filière nucléaire. Commissariat Général au Plan.

Cropper M.L. (1980). Pollution aspects of nuclear energy use. Journal of Environmental Economics and Management, 7, 334-52.

Greene, R. (1999). An Assessment of Energy and Environmental Issues Related to the Use of Gas-to -Liquid Fuels in Transportation, ORNL-258, Oak Ridge National Laboratory, Oak Ridge, TM.

Hoffert Martin, et al. (2002), Advanced Technology Paths to Global Climate Stability: Energy for a Greenhouse Planet, Science 298 (November), 981-87.

Hore-Lacy, I. (2003), Nuclear Electricity, Seventh Edition. Uranium Information Center Ltd. and World Nuclear Association.

Hotelling, H. (1931), The Economics of Exhaustible Resources, Journal of Political Economy, 39, 137-75.

IEA (International Energy Agency) (2000). Oil Prices and Taxes in the Year 2000, An IEA Statistical Fact Sheet. International Energy Agency (IEA-OECD), Paris, France.

IEA (2001). World Energy Outlook 2001. International Energy Agency (IEA-OECD), Paris, France.

Lutz, W., W. Sanderson and S. Scherbov (2001). The End of World Population Growth, Nature, 412, 54346.

Manne, A., and R. Richels (2002). The Impact of Learning-By-Doing on the Timing and Costs of $\mathrm{CO}_{2}$ Abatement, working paper, Stanford University, Stanford, California.

Massachusetts Institute of Technology (2003). The Future of Nuclear Power. An Interdisciplinary MIT Study. Available online: http://web.mit.edu/nuclearpower/.

Moniz, E. (1999), Shaping the Nuclear Future, Annual International Symposium, The Uranium Institute.

Nakicenovic, N., and K. Riahi (2001). An Assessment of Technological Change across Selected Energy Scenarios, A IIASA-World Energy Council publication.

NEA (Nuclear Energy Agency) (1994). The Economics of the Nuclear Fuel Cycle. NEA-OECD publication, Paris, France. 
NEA (2001). Nuclear Energy Data 2001. NEA-OECD publication, Paris, France.

NEA (2002). Accelerator-driven Systems (ADS) and Fast Reactors (FR) in Advanced Nuclear Fuel Cycles: A Comparative Study. NEA-OECD publication, Paris, France.

Nordhaus, W D. (1973). The Allocation of Energy Resources, Brookings Papers on Economic Activity, 3, $529-70$

Nordhaus, W.D. (1979). The Efficient Use of Energy Resources, New Haven: Yale University Press.

Nordhaus, W.D. (1997). The Swedish Nuclear Dilemma, Resources For the Future, Washington, DC.

Nordhaus, W.D., and J. Boyer (2000). Warming the World : Economic Models of Global Warming, MIT

Press, Cambridge, MA.

OECD (2000a). Uranium 1999, Resources, Production and Demand. NEA-OECD and IAEA publication, Paris, France.

OECD (2000b). Experience Curves for Energy Technology Policy. OECD publication, Paris, France.

Parry, I.W.H. (1997). Productivity trends in natural resource industries, Resources For the Future Discussion Paper \#97-39, Washington, DC.

Radetzki, M. (2000). Coal or Nuclear in New Power Stations : The Political Economy of an Undesirable but Necessary Choice, The Energy Journal, 21, 135-147.

The New York Times (2003). Will Calgary be the Next Kuwait? by Manik Talwani, Aug. 14.

United Nations (2002). World Population Prospects: The 2002 Revision, Highlights. United Nations publications.

Viscusi, W.K. (1992). Fatal Tradeoffs: Public and Private Responsibilities for Risk, New York: Oxford University Press.

World Nuclear Association (2003), Nuclear Power in the World Today, Information and Issue Brief, June. 


\section{Appendix A. Specification of the Nuclear Technology}

\section{Overview of the Technology}

Uranium is the main raw material used in the generation of nuclear power. Almost two thirds of the world's uranium reserves are found in four countries - Australia, Kazakhstan, Canada and South Africa. ${ }^{22}$ In the Light Water Reactor (LWR), which is the most common technology used, mined uranium ore is enriched from $0.7 \%$ to $3.5 \% .{ }^{23}$ This uranium fissions to produce heat which is converted into steam that drives a turbine and produces electricity. The spent fuel contains most of the original uranium and some plutonium. This recovered uranium can be reprocessed, enriched and mixed with the plutonium in the spent fuel to produce a mixed oxide fuel that can be put into long term storage or reprocessed. We also consider a modern nuclear technology, the Fast Breeder Reactor (FBR), prototypes of which are operational in several countries. These reactors are more efficient in using uranium. They use plutonium as basic fuel but also produce it as waste. The FBR can extract approximately 60 times more energy from each ton of uranium than the conventional LWR. However, its higher capital costs and the present low price of uranium makes the FBR uneconomical. ${ }^{24}$ About 20 FBR reactors are currently in operation.

About 434 nuclear reactors are in service globally, representing an installed production capacity of 351 Gigawatts $(\mathrm{GW})$. Another 36 reactors are currently under construction. Aggregate estimated reserves of uranium ore, including those already discovered and those recoverable at high cost, are estimated to be nearly 15.4 million tons (OECD, 2000a). We consider a single grade of uranium, but perform sensitivity analysis with a doubling of the stock. ${ }^{25}$

\section{Modelling the Nuclear Technology}

The technology is briefly described here (for details, see NEA, 1994). Natural uranium is enriched for use in a LWR plant or used directly in a FBR plant. Production of nuclear power from LWR technology is assumed to be a linear function of the enriched uranium input. The enrichment process creates large quantities of depleted uranium, which cannot be used in the LWR but has economic value as an input in the FBR fuel mix. The two technologies are characterized by the existence of joint products: by-products

\footnotetext{
${ }^{22}$ These reserves are recoverable at uranium prices of up to $\$ 80 / \mathrm{kg}$ (current prices are about $\$ 30 / \mathrm{kg}$ ). At substantially higher prices, seawater could be tapped for large amounts of the metal.

${ }^{23}$ To facilitate comparison, weapons programs require uranium enrichment of over $90 \%$.

${ }^{24}$ This low price is partly due to the availability of weapons grade uranium and plutonium from military stockpiles of the US and the former Soviet Union. This higher grade uranium is blended down to provide reactor fuel. It currently provides almost $15 \%$ of the world's annual uranium supply.

${ }^{25}$ Our estimates, computed independently, are similar to those developed by a recent interdisciplinary MIT (2003) study (16 million tonnes).
} 
from LWR production such as plutonium, are used as an input into FBR production. The LWR technology produces three different by-products: fissile waste which must be treated and stored, and plutonium and reprocessed uranium, both of which can be used in FBR reactors. These complementarities in material flows are shown in Fig. A1.

Consider a single deposit of low grade uranium ore starting at point $\mathrm{A}$ in the figure. Natural uranium could be enriched for use in a LWR plant or used directly without enrichment in a FBR facility. Define $u_{E}^{L}$ as the instantaneous flow of natural uranium that is enriched and used in a LWR plant. Enriching the ore leads to the separation of uranium into enriched uranium $\left(u_{E}^{L}\right)$ and depleted uranium $\left(u_{D}^{L}\right)$. Let these ratios be $\varepsilon$ and $1-\varepsilon$, respectively, with $0<\varepsilon<1$. Then $u_{E}^{L}=\varepsilon u_{N}^{L} \quad$ and $\quad u_{D}^{L}=(1-\varepsilon) u_{N}^{L}$. Let $q^{L}$ be the instantaneous production of energy (electricity) from LWR technology. We assume that production of energy is a linear function of enriched uranium $u_{E}^{L}=\alpha^{L} q^{L}$. The LWR technology produces three different by-products - fissile waste which cannot be re-used and must be stored; plutonium, and reprocessed uranium. The last two can be re-used in fast breeder reactors (FBR). The amount of plutonium produced by LWR technology is denoted by $P u^{L}$ and is assumed to be proportional to the instantaneous production rate $q^{L}$, i.e., $P u^{L}=\beta^{L} q^{L}$. The amount of reprocessed uranium is similarly given by $u_{R}^{L}=\xi^{L} q^{L}$. The volume of wastes $w^{L}$ generated by LWR technology is given by $w^{L}=\gamma^{L} q^{L}$, where $\alpha^{L}, \beta^{L}, \gamma^{L}$ and $\xi^{L}$ are given positive coefficients.

Let $q^{F}$ be the corresponding production of energy from FBR technology. Again, we assume this to be a linear function of natural, depleted or reprocessed uranium, denoted respectively by $u_{N}^{F}, u_{D}^{F}$ and $u_{R i}^{F}$, where the subscript $i$ denotes input. The content of uranium U-235 in natural uranium is greater than in depleted uranium, but for simplicity we assume that they are perfect substitutes so that $u_{N}^{F}+u_{D}^{F}+u_{R i}^{F}=\alpha^{F} q^{F}$. This is shown by point $\mathrm{B}$, where the stocks of natural, depleted and reprocessed uranium are merged into one. The unique feature of FBR technology is that it can reuse part of the plutonium produced. Therefore the choice of the breeding ratio, i.e., the input-output ratio of plutonium, denoted by $\mu^{F}$ is endogenous. Thus the input of plutonium is given by $P u_{i}^{F}=\beta^{F} q^{F}$ and the output (denoted by subscript o ) by $P u_{o}^{F}=\mu^{F} \beta^{F} q^{F}$. The uranium and plutonium inputs in FBR must be used in fixed proportion $k$. Their complementarity is described by the relationship $\frac{u_{N}^{F}+u_{D}^{F}+u_{R i}^{F}}{P u_{i}^{F}} \equiv k=\frac{\alpha^{F}}{\beta^{F}}$. 
The output of reprocessed uranium from FBR technology is denoted by $u_{R o}^{F} \cdot{ }^{26}$ Its proportion is given by $u_{R o}^{F}=\xi^{F} q^{F}$. Let $w^{F}$ represent the amount of waste generated by the FBR technology. Then $w^{F}=\gamma^{F} q^{F}$. Again, $\alpha^{F}, \beta^{F}, \gamma^{F}$ are positive constants. In summary, FBR technology uses uranium (natural, depleted and reprocessed) and plutonium as inputs, and produces energy, reprocessed uranium, plutonium and waste fissile material.

The two technologies are somewhat complementary. Natural uranium must be enriched before use in a LWR plant. This enrichment process increases the proportion of fissile uranium which sustains the chain reaction in a LWR reactor. The process of enrichment also generates large quantities of depleted (lower grade) uranium, which needs to be stockpiled, and has little economic value. However, this depleted uranium can be used in FBR technology, along with plutonium. Thus, the waste material from enrichment can be put to use in FBR reactors, producing yet more plutonium which can be used again.

\section{Stock Dynamics}

We consider five distinct stocks of resources: natural uranium (in the ground), depleted uranium, reprocessed uranium, stockpiled plutonium, and nuclear wastes. The stock of uranium ore in the ground, $U_{N}(t)$ is enriched and declines by the quantity extracted for LWR, $u_{N}^{L}(t)$ and FBR, $u_{N}^{F}(t)$ given by $\dot{U}_{N}(t)=u_{N}^{L}(t)-u_{N}^{F}(t)$. The stock of depleted uranium $U_{D}(t)$ is augmented by the depleted uranium which is rejected from the enrichment process $u_{D}^{L}(t)=(1-\varepsilon) u_{N}^{L}(t)$, and diminished by the extracted quantity to be used in FBR, $u_{D}^{F}(t)$ given by $\dot{U}_{D}(t)=(1-\varepsilon) u_{N}^{L}(t)-u_{D}^{F}(t)$. The stock of reprocessed uranium $U_{R}(t)$ is augmented by the reprocessed uranium $u_{R}^{L}(t)$ from LWR and $u_{R o}^{F}(t)$ from FBR, and diminished by the quantity $u_{R i}^{F}(t)$ to be used in FBR, and is given as $\dot{U}_{R}(t)=u_{R}^{L}(t)-u_{R i}^{F}(t)+u_{R o}^{F}(t)$. The stock of plutonium $P u(t)$ is augmented by the quantity $\beta^{L} q^{L}(t)$ out of the LWR plant, diminished by FBR input $\beta^{F} q^{F}$, and augmented by the amount of plutonium created by the FBR technology, $\mu^{F} \beta^{F} q^{F}$ with $\mu^{F}>1$. Now define $\Delta$ as the time lag between the date at which the plutonium flow $r_{o}^{F}$ is extracted from the reactor and the date at which it is reintegrated into the plutonium stock for re-use, caused by the need to reduce the temperature of the mineral and other processing tasks. This is given by

\footnotetext{
${ }^{26}$ The uranium input and output also need to be used in fixed proportions, satisfying the condition $u_{N t}^{F}+u_{D t}^{F}+u_{R i t}^{F} \equiv u_{R o t}^{F}\left(\frac{\alpha^{F}}{\xi^{F}}\right)$.
} 


$$
P \dot{u}(t)=p u_{o}^{F}(t)-p u_{i}^{F}(t)+p u_{o}^{F}(t)=\beta^{L} q^{L}(t)-\beta^{F} q^{F}(t)+\beta^{F} \mu(t-\Delta) q^{F}(t-\Delta) .
$$

Finally, the flow of wastes from the two technologies, $w^{L}$ and $w^{F}$ are aggregated as follows:

$\dot{W}(t)=w^{L}(t)+w^{F}(t)$. We assume zero radioactive decay of the nuclear waste because of the relatively short time horizon of the model.

\section{Cost Functions for Nuclear Technology}

Let $m$ denote the average extraction cost of natural uranium, so that the total extraction cost is $m\left(u_{N}^{L}+u_{N}^{F}\right)$. Let $m^{S}$ be the unit enrichment (separation) cost of uranium used in LWR. Then the total enrichment cost is equal to $m^{S} u_{N}^{L}$. This enriched uranium must then be packaged and assembled before use as an input in LWR production, at an average cost of $m^{L}$. Therefore, the total preparation cost of LWR uranium is $m^{L} u_{E}^{L}=m^{L} \varepsilon u_{N}^{L}$. The average cost of fuel reprocessing for LWR technology is denoted by $m_{R}^{L}$, so that the associated total cost is equal to $m_{R}^{L}\left[\beta^{L}+\gamma^{L}+\xi^{L}\right] q^{L}$. Finally, the LWR reactor incurs an in situ operating cost, equal to $v^{L} q^{L}$.

Let $m_{f}^{F}$ and $m_{R}^{F}$ denote the average preparation and reprocessing cost of FBR fuel, respectively. Then the total FBR fuel fabrication cost is $m_{f}^{F}\left[u_{N}^{F}+u_{D}^{F}+u_{R i}^{F}+r_{i}^{F}\right]$ and the total fuel reprocessing cost is $m_{R}^{F}\left[\mu \beta^{F}+\gamma^{F}+\xi^{F}\right] q^{F}$. The operating cost of FBR technology is given by $v^{F} q^{F}$. Each unit of depleted uranium is stockpiled at an average annual cost of storage of $s_{U_{D}}$, so that the total storage cost is $s_{U_{D}} U_{D}$.

Similarly, let the respective annual unit cost of storage for reprocessed uranium and plutonium be $s_{U_{R}}$ and $s_{P u}$ so that the corresponding storage costs are $s_{U_{R}} U_{R}$ and $s_{P u} P u$. Finally the annual unit cost of storage for reprocessed uranium is given by $s_{W}$ so that the total cost is given by $s_{W}\left[\gamma^{L} q^{L}+\gamma^{F} q^{F}\right]$

\section{Optimization}

Production of nuclear energy is optimized by choosing the instantaneous amount of power generated by the two technologies, $q^{L}(t)$ and $q^{F}(t)$ and the breeding ratio $\mu^{F}(t)$, which maximizes a social surplus function, net of total costs. Denote the instantaneous gross surplus as $S(t)=S\left(q^{L}(t)+q^{F}(t)\right)$. With a constant social rate of discount $\delta$, we have 


$$
\begin{aligned}
\underset{\left\{q^{L}(t)\right\},\left\{q^{F}(t)\right\},\left\{\mu^{F}(t)\right\}}{\operatorname{Max}} \int_{0}^{\infty}\left\{S\left(q^{L}(t)+q^{F}(t)\right)\right. & -m\left[u_{N}^{L}(t)-u_{N t}^{F}(t)\right]-\left[m^{S}+\varepsilon m_{f}^{L}\right] u_{N t}^{L}(t) \\
& -m_{R}^{L}\left[\beta^{L}+\gamma^{L}+\xi^{L}\right] q^{L}(t)-v^{L} q^{L}(t) \\
& -m_{f}^{F}\left[u_{N}^{F}(t)+u_{D}^{F}(t)+u_{R i}^{F}(t)+r_{i}^{F}(t)\right] \\
& -m_{R}^{F}\left[\mu(t) \beta^{F}+\gamma^{F}+\xi^{F}\right] q^{F}(t)-v^{F} q^{F}(t) \\
& -s_{U_{D}} \cdot U_{D}(t)-s_{U_{R}} U_{R}(t)-s_{P u} \cdot P u(t) \\
& \left.-s_{W} \cdot\left[\gamma^{L} q^{L}(t)+\gamma^{F} q^{F}(t)\right]\right\} e^{-\delta t} d t
\end{aligned}
$$

subject to the constraints defined above. The set of necessary conditions for the above model is not provided here but is available from the authors.

\section{Appendix B. Data}

\section{A. Nuclear Data}

Aggregate estimated reserves of uranium ore, including those already discovered and those recoverable at a higher cost, have been estimated to be of the order of 15.4 million tons (OECD, 2000a). We consider a single grade of uranium. ${ }^{27}$ The actual cumulative production of nuclear power since the technology was deployed now exceeds $34,000 \mathrm{TWh}\left(1 \mathrm{TWh}=10{ }^{9} \mathrm{KWh}\right)$. This implies that approximately one million tons of plutonium and 0.1 million tons of fissile waste have been produced, including discharged uranium and other fission by-products. ${ }^{28}$ These values are used as initial stocks. The initial stock of reprocessed uranium is assumed to be zero (see Table B1).

LWR technology is modeled on the European Pressurized Reactor (EPR) with a capacity of 1450 MWe, producing 11.46 TWh of power annually. The spent fuel discharge consists of 19.132 tons of uranium, 0.271 tons of plutonium and other fission products (see Charpin, 2000). After reprocessing and cooling, each TWh of electrical energy generates $23 \mathrm{~kg}$ of plutonium and $120.5 \mathrm{~kg}$ of wastes. ${ }^{29}$

FBR technology is based on the European Fast Reactor (EPR) with a capacity of 1000 MWe, producing 8.76 TWh of power. This plant requires 11.7 tons of uranium and 1.5 tons of plutonium annually. The spent fuel discharge consists of 10.4 tons of uranium, one ton of fission products and 0.3 tons of

\footnotetext{
${ }^{27}$ The additional benefits of modeling with multiple uranium ores is low, since the total stock is small enough to be exhausted by use in LWR plants within a few decades.

${ }^{28}$ During this period, $(1-\varepsilon)$ or 0.917 million tons of depleted uranium have been stockpiled (OECD, 2000a).

${ }^{29} \mathrm{LWR}$ waste production decreases with FBR operation because of reprocessing of spent fuels.
} 
plutonium, which is recycled back into the plant. Table B2 provides a summary for both technologies. ${ }^{30}$

Long-run cost estimates for nuclear power are obtained from NEA (1994, 2001, 2002). We have simplified the specification of the technology and regrouped some stages whose costs are low or which involve a transformation of products without any storage. A common feature of the nuclear cycle is the existence of joint products. For instance, the operation of a LWR plant produces reprocessed uranium which can be used in FBR technology. In such cases, the costs of reprocessing or storage are apportioned between the two technologies. For simplicity, we assume constant returns to scale technologies and unit costs that are fixed over time. It is likely that technological change and the costs of labor, capital and materials may alter relative costs over time. It is difficult to predict these changes ex ante, but we partly address this issue by applying across the board technology-induced cost reductions.

The unit cost of extraction of uranium oxide and its conversion to uranium hexafluoride is assumed to be $\$ 60 / \mathrm{kg}$ of uranium. The separation and enrichment stage involves processes that add significant value to the mineral. ${ }^{31}$ The cost of enrichment is taken to be $\$ 76 / \mathrm{kg}$ of uranium. The fuel fabrication stage also represents a significant part of the fuel cycle cost and depends largely on the type of reactor. It is assumed to be $\$ 305 / \mathrm{kg}$ for LWR fuels, and a high $\$ 3,050 / \mathrm{kg}$ for FBR fuels, partly because of additional safety measures associated with the handling of large amounts of plutonium. The unit cost of reprocessing spent fuel is assumed to be $\$ 500 / \mathrm{kg}$ for LWR and $\$ 1,600 / \mathrm{kg}$ for FBR.

Investment and direct operating costs represent the largest fraction of total cost in electricity generation. They are assumed to be $\$ 5.614 / \mathrm{mmBtu}$ of delivered electricity for LWR, and $50 \%$ higher for FBR. The disposal cost of depleted uranium is assumed to be $\$ 2.5 / \mathrm{kg}$. The cost of interim storage of plutonium is a high $\$ 1,000 / \mathrm{kg}$, because of its toxicity. The cost of conditioning of the waste and long-term geological storage is assumed to be independent of the source of the waste material (LWR or FBR) and is taken to be $\$ 500 / \mathrm{kg}$. Table B3 provides a summary of the cost estimates.

\section{B. Other Energy Data}

The baseline sectoral elasticities and technical coefficients are taken from Nordhaus (1979) and Chakravorty et al. (1997) respectively, and they are given in Table B4. The extraction costs by resource

\footnotetext{
${ }^{30}$ For a more comprehensive description, see Hore-Lacy (2003) and Brown (2002).

${ }^{31}$ Separation produces a large quantity of stockpiled depleted uranium. Recall that this stock is waste in a LWR operation, but is an important source of uranium for FBR technology.
} 
and grade are given in Table B5. ${ }^{32}$ These reserves include known unconventional reserves (e.g., oil and gas in shales and tar sands). ${ }^{33,34}$ The cost of solar photovoltaic energy is taken to be 25 cents $/ \mathrm{kWh} .{ }^{35}$ The carbon ceiling is in the form of the concentration of atmospheric $\mathrm{CO}_{2}$ equal to 550 parts per million. Various climate studies have used 450-650 ppm (e.g., Manne and Richels, 2002). ${ }^{36}$ We perform a sensitivity analysis over the entire range. Atmospheric concentrations are computed using carbon emission rates from Nordhaus and Boyer (2000), after adjusting for the different time intervals in our model ${ }^{37}$ The discount rate is assumed to be $2 \%$.

The GDP growth rate assumptions are the same for all the models except model E. In the former, we assume a steady decline in GDP growth over time, shown in Fig. B1. As in Chakravorty et al. (1997), global GDP is expected to grow over time at an initial rate of 3\% every year. This growth rate declines at the rate of $10 \%$ every decade. For model E, we consider an increase in the GDP growth rate in the near term followed by a decline, which reflects more accurately the expected sharp decline in population and the inevitable satiation in per capita energy use in the long run (see Fig. B1). The rate of GDP growth declines geometrically at $5 \%$ per decade until 2060 , and at $10 \%$ per decade beyond this period. Decadal GDP growth is close to zero (less than $0.5 \%$ ) around 2110 and $0.1 \%$ around year 2250 . Fig. B2 shows the underlying population and GDP per capita assumptions. World GDP has been calibrated so that per capita GDP asymptotically reaches the value of $\$ 25,500$, the current level in the United States.

\footnotetext{
${ }^{32}$ Several deposits of a resource each with constant extraction cost may approximate a cost function that increases with cumulative extraction, as assumed in several studies (e.g., Nordhaus and Boyer, 2000).

${ }^{33}$ For instance, recoverable shale oil reserves are estimated to be of the same order of magnitude as oil reserves in the two most oil-rich OPEC countries - Saudi Arabia and Iraq, each with approximately 230260 billion barrels (The New York Times, 2003). Hydrocarbon reserves in the ocean bed are estimated to be several orders of magnitude higher, albeit available at a significantly higher cost.

${ }^{34}$ The unit cost of oil per barrel is $\$ 10$ for the higher grade (IEA, 2000) $(\$ 1 / \mathrm{bbl}=0.18 \$ / \mathrm{mmBtu})$ and $\$ 21$ (Chakravorty et al., 1997) for the lower grade. The unit costs for the higher grade of gas is $\$ 1.75 / \mathrm{mmBtu}$, and for the lower grade, $\$ 2.76 / \mathrm{mmBtu}$, which corresponds to the third quartile of the distribution of gas extraction costs (Greene, 1999). The unit cost for the three grades of coal are \$1.36, 2.37 and 5.08 per ton respectively $(\$ 1 / \mathrm{mmBtu}=\$ 15.02 /$ ton of coal $)$.

${ }^{35} \mathrm{~A}$ vector of conversion costs from each resource to each demand is added to the extraction cost. The total cost is shown in Table B5.

${ }^{36}$ Current $\mathrm{CO}_{2}$ concentration levels are approximately $370 \mathrm{ppm}$. A target of $550 \mathrm{ppm}$ is expected to produce some warming but without catastrophic effects (Hoffert et al., 2002).

${ }^{37}$ In the case of modern nuclear technology, the algorithm is run over 5 year intervals, since reprocessing of the spent fuel takes approximately 5 years. Nordhaus and Boyer use 10 year intervals, so we adjusted their emission rates correspondingly.
} 


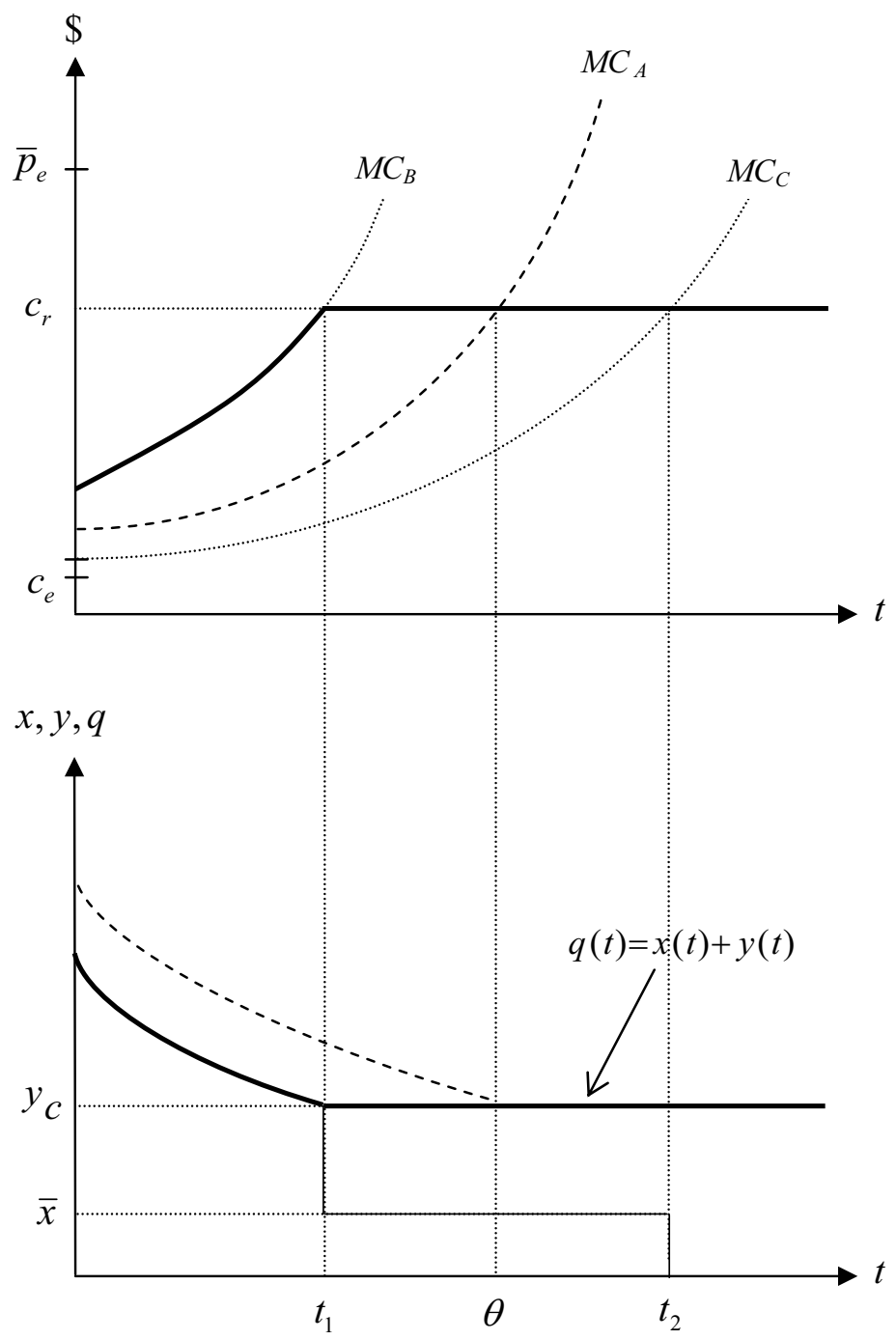

Fig. 1: Both the Polluting Fossil Fuel and the Clean Renewable are used at the Ceiling 


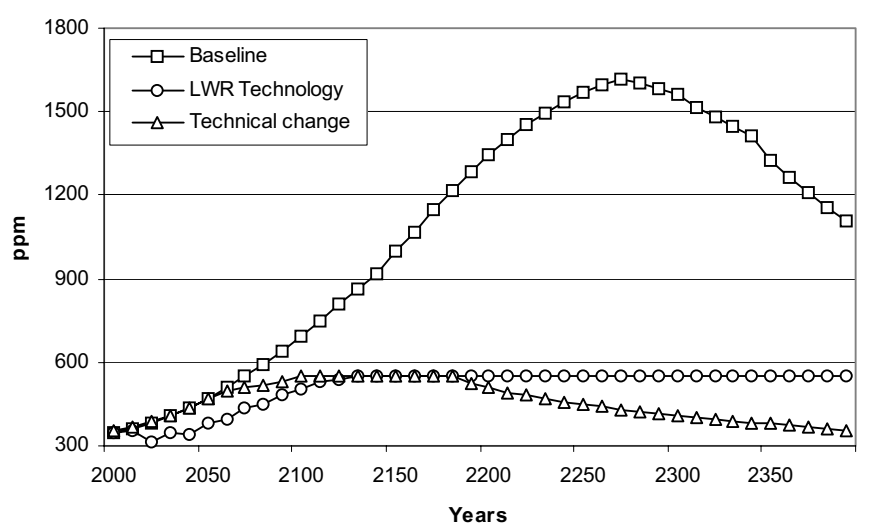

Fig. 2: Time Path of Carbon Concentration

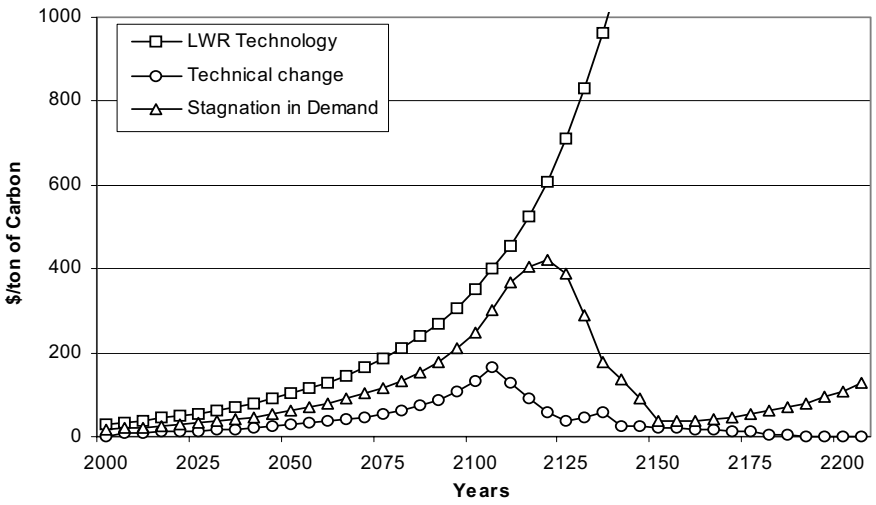

Fig. 3: Time Path of Carbon Prices

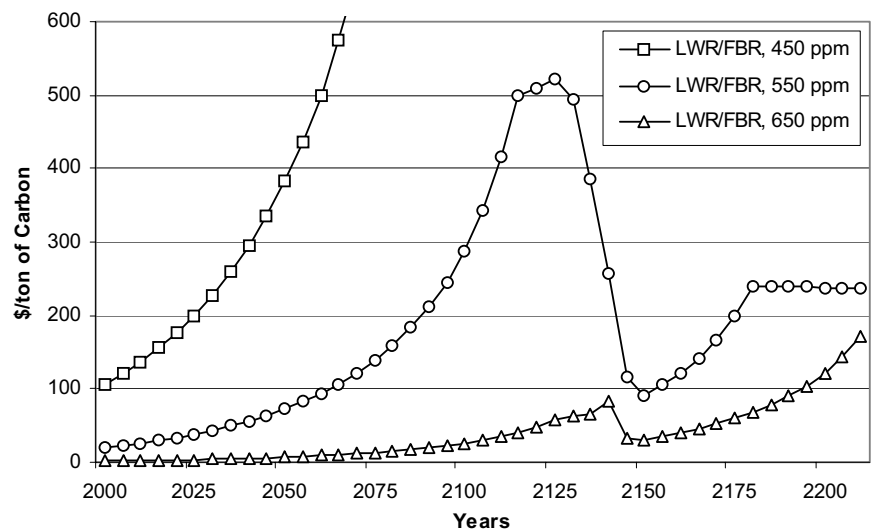

Fig. 4: The Price of Carbon under Alternative Carbon Targets 


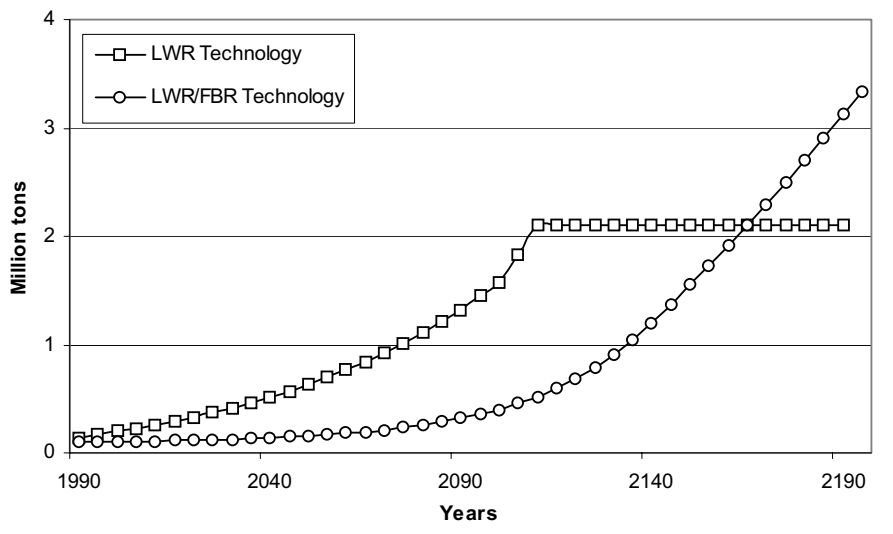

Fig. 5: Cumulative Stock of Nuclear Waste

Table 1: Resource Use in the Baseline Model with Fossil Fuel (No Nuclear)

\begin{tabular}{|c|c|c|c|c|}
\hline \multirow[b]{2}{*}{ Decade } & \multicolumn{4}{|c|}{ Baseline, Fossil Fuels, no Nuclear Pow er } \\
\hline & Elec. & Transp. & Resid. / Com. & Ind. \\
\hline 1990-99 & Coal I & Oill & Gas I & Gas I \\
\hline 2000-09 & Coal I & Oil I & Gas I & Gas I \\
\hline 2010-19 & Coal I & Oil I & Gas I & Gas I \\
\hline $2020-29$ & Coal I & Oil I & Gas I & Gas I \\
\hline 2030-39 & Coal I & Oil I & Gas I & Gas I \\
\hline $2040-49$ & Coal I & Oil I & Gas ॥ & Gas HII \\
\hline $2050-59$ & Coal I & Oil I & Gas ॥ & Gas ॥ \\
\hline $2060-69$ & Coal I & Oil I-II & Gas ॥ & Gas ॥ \\
\hline $2070-79$ & Coal I & Oil II & Gas ॥ & Gas ॥ \\
\hline 2080-89 & Coal I & Oil II & Gas ॥ & Gas II / Coal I \\
\hline $2090-99$ & Coal IIII & Oil II & Gas II & Coal II \\
\hline $2100-09$ & Coal II & Oil II & Gas ॥ & Coal II \\
\hline $2110-19$ & Coal II & Oil II & Gas ॥ & Coal II \\
\hline $2120-29$ & Coal II & Oil II & Gas ॥ & Coal II \\
\hline $2130-39$ & Coal II & Oil II & Coal II & Coal II \\
\hline $2140-49$ & Coal II & Oil II / Coal II & Coal II & Coal II \\
\hline $2150-59$ & Coal II & Coal II & Coal II & Coal II \\
\hline $2160-69$ & Coal II & Coal II & Coal II & Coal II \\
\hline $2170-79$ & Coal II & Coal II & Coal II & Coal II \\
\hline $2180-89$ & Coal II & Coal II & Coal II & Coal II \\
\hline 2190_99 & Coal II & Coal II & Coal II & Coal II \\
\hline $2200-09$ & Coal II & Coal II & Coal II & Coal II \\
\hline $2210-19$ & Coal III & Coal II-III & Coal II & Coal III \\
\hline $2220-29$ & Coal III & Coal III & Coal III & Coal III \\
\hline$\ldots$ & $\ldots$ & $\ldots$ & $\ldots$ & $\ldots$ \\
\hline $2260-69$ & Coal III / Solar & Coal III & Coal III & Coal III \\
\hline $2270-79$ & Solar & Coal III & Coal III & Coal III \\
\hline $2280-89$ & Solar & Coal III & Coal III & Coal III \\
\hline $2290-99$ & Solar & Solar & Coal III & Coal III \\
\hline$\ldots$ & $\ldots$ & $\ldots$ & $\ldots$ & $\ldots$ \\
\hline $2330-39$ & Solar & Solar & Solar & Solar \\
\hline$\ldots$ & $\ldots$ & $\ldots$ & $\ldots$ & $\ldots$ \\
\hline
\end{tabular}


Table 2: Percentage Shares of Primary Energy Supply

\begin{tabular}{|c|c|c|c|c|c|c|c|c|c|c|c|c|}
\hline \multirow[t]{2}{*}{ Scenarios } & \multicolumn{3}{|c|}{ Oil } & \multicolumn{3}{|c|}{ Gas } & \multicolumn{3}{|c|}{ Coal } & \multicolumn{3}{|c|}{ Nuclear ${ }^{1}$} \\
\hline & 2020 & 2050 & 2100 & 2020 & 2050 & 2100 & 2020 & 2050 & 2100 & 2020 & 2050 & 2100 \\
\hline Baseline & 16 & 13 & 12 & 71 & 70 & 38 & 16 & 18 & 50 & - & - & - \\
\hline LWR & 14 & 14 & 44 & 70 & 70 & 41 & 11 & 11 & 4 & 5 & 6 & 11 \\
\hline LWR/FBR & 13 & 13 & 11 & 71 & 71 & 53 & 8 & 4 & 0 & 7 & 13 & 44 \\
\hline Tech. Prog. & 23 & 33 & 6 & 71 & 37 & 25 & 0 & 16 & 0 & $7(0)$ & $10(5)$ & $5(54)$ \\
\hline Stag. Dem. & 13 & 13 & 11 & 72 & 72 & 51 & 8 & 4 & 0 & 7 & 11 & 38 \\
\hline
\end{tabular}

(1) Solar shares are in brackets.

Table 3: Resource Use under a Carbon Target and (a) Traditional (LWR) and (b) both Nuclear Technologies (LWR, FBR)

\begin{tabular}{|c|c|c|c|c|}
\hline \multirow[b]{2}{*}{ Decade } & \multicolumn{4}{|c|}{ Baseline, LWR, 550 ppm target } \\
\hline & Elec. & Transp. & Resid. / Com. & Ind. \\
\hline $1990-99$ & Oil I/LWR & Oill & Gas I & Gas I \\
\hline 2000-09 & Coal I / LWR & Oil I & Gas I & Gas I \\
\hline 2010-19 & Coal I / LWR & Oill & Gas I & Gas I \\
\hline $2020-29$ & Coal I / LWR & Oil I & Gas I & Gas I \\
\hline 2030-39 & Coal I/ LWR & Oil I & Gas I & Gas I \\
\hline $2040-49$ & Coal I/ LWR & Oil I & Gas I & Gas I-II \\
\hline $2050-59$ & Coal I / LWR & Oil I & Gas II & Gas II \\
\hline $2060-69$ & Coal I/ LWR & Oil I-II & Gas II & Gas II \\
\hline $2070-79$ & Coal I/ LWR & Oil II & Gas II & Gas II \\
\hline $2080-89$ & Coal I/ LWR & Oil II & Gas II & Gas II / Oil II \\
\hline 2090-99 & Coal I/ LWR & Oil II & Gas II & Oil II \\
\hline 2100-09 & Coal I / LWR & Oil II & Gas II & Oil II \\
\hline $2110-19$ & Solar/LWR & Oil II & Gas II & Coal I \\
\hline $2120-29$ & Solar / LWR & Oil II & Gas II & Coal I / Gas II \\
\hline $2130-39$ & Solar & Oil II & Gas II & Coal I / Gas II \\
\hline $2140-49$ & Solar & Oil II / Sol. & Gas II & Coal I \\
\hline $2150-59$ & Solar & Oil II / Sol. & Gas II & Coal I \\
\hline $2160-69$ & Solar & Solar & Gas II & Coal I \\
\hline $2170-79$ & Solar & Solar & Gas II & Coal I \\
\hline $2180-89$ & Solar & Solar & Coal I / Sol. & Coal I \\
\hline 2190-99 & Solar & Solar & Coal I-II / Sol. & Coal I \\
\hline $2200-09$ & Solar & Solar & Coal II / Sol. & Coal II \\
\hline $2210-19$ & Solar & Solar & Coal II / Sol. & Coal II \\
\hline $2220-29$ & Solar & Solar & Coal II / Sol. & Coal II \\
\hline$\ldots$ & $\ldots$ & $\ldots$ & $\ldots$ & $\ldots$ \\
\hline $2260-69$ & Solar & Solar & Coal II / Sol. & Coal II \\
\hline $2270-79$ & Solar & Solar & Coal II / Sol. & Coal II \\
\hline $2280-89$ & Solar & Solar & Coal II / Sol. & Coal II \\
\hline $2290-99$ & Solar & Solar & Coal II / Sol. & Coal II \\
\hline$\ldots$ & $\ldots$ & $\ldots$ & $\ldots$ & $\ldots$ \\
\hline $2330-39$ & Solar & Solar & Coal II / Sol. & Coal II \\
\hline
\end{tabular}

(a)

\begin{tabular}{|c|c|c|c|}
\hline \multicolumn{4}{|c|}{ Baseline, LWR-FBR, 550 ppm target } \\
\hline Elec. & Transp. & Resid. / Com. & Ind. \\
\hline Gas I/LWR & Oil I & Gas I & Gas I \\
\hline Gas-Coal I /LWR & Oil I & Gas I & Gas I \\
\hline Coal I/LWR & Oill I & Gas I & Gas I \\
\hline Coal I/ LWR & Oill & Gas I & Gas I \\
\hline Coal I/ LWR & Oil I & Gas I & Gas I \\
\hline Coal I/ LWR & Oil I & Gas I-II & Gas I-II \\
\hline Coal I/ LWR & Oil I & Gas II & Gas II \\
\hline LWR & Oil I-II & Gas II & Gas II \\
\hline LWR / FBR & Oil II & Gas II & Gas II \\
\hline LWR / FBR & Oil II & Gas II & Gas II \\
\hline FBR & Oil II & Gas II & Gas II /LWR /FBR \\
\hline FBR & Oil II / Gas II & Gas II & Gas II /LWR /FBR \\
\hline FBR & Oil II / Gas II & Gas II / FBR & LWR / FBR \\
\hline FBR & Oil II & Gas II / FBR & FBR \\
\hline FBR & Oil II & Gas II / FBR & FBR \\
\hline FBR & Oil II & FBR & FBR \\
\hline FBR & Oil II & FBR & FBR \\
\hline FBR & Oil II / Coal I & FBR & FBR \\
\hline FBR & Coal I / FBR & FBR & FBR \\
\hline FBR & Coal I / FBR & FBR & FBR \\
\hline FBR & Coal I/ FBR & FBR & FBR \\
\hline FBR & Coal I / FBR & FBR & FBR \\
\hline FBR & Coal I / FBR & FBR & FBR \\
\hline FBR & Coal I / FBR & FBR & FBR \\
\hline$\ldots$ & $\ldots$ & $\ldots$ & $\ldots$ \\
\hline FBR & Coal I/ FBR & FBR & FBR \\
\hline FBR & Coal I / FBR & FBR & FBR \\
\hline FBR & Coal I / FBR & FBR & FBR \\
\hline FBR & Coal I-II / FBR & FBR & FBR \\
\hline$\ldots$ & $\ldots$ & $\ldots$ & $\ldots$ \\
\hline FBR & Coal II / FBR & FBR & FBR \\
\hline$\ldots$ & $\ldots$ & $\ldots$ & $\ldots$ \\
\hline
\end{tabular}

(b) 
Table 4: Scarcity Rent of Uranium and Shadow Price of Carbon in Year 2000

\begin{tabular}{lccc}
\hline \hline \multicolumn{1}{c}{ Scenarios } & $\begin{array}{c}\text { Carbon Targets } \\
(\mathrm{ppm})\end{array}$ & $\begin{array}{c}\text { Scarcity Rent of } \\
\text { Uranium }(\$ / \mathrm{kg})\end{array}$ & $\begin{array}{c}\text { Shadow Price of } \\
\text { Carbon }(\$ / \text { ton })\end{array}$ \\
\hline LWR Technology & 450 & 1542 & 87 \\
& 550 & 1542 & 40 \\
& 650 & 1143 & 21 \\
\hline LWR Technology and & 550 & 697 & 32 \\
Doubling of Uranium Stock & & 176 & 137 \\
\hline & 450 & 160 & 26 \\
Both Nuclear Technologies & 550 & 163 & 10 \\
\hline Both Nuclear Technologies and & 650 & 17 & 22 \\
Technical Progress & 550 & 95 & \\
\hline Stagnation in Demand Growth & 550 & & \\
\hline (1) 30.8 million tons. & & & \\
\hline
\end{tabular}

Table 5: Resource Use with a Carbon Target and Exogenous Decline in Costs

\begin{tabular}{|c|c|c|c|c|}
\hline \multirow[b]{2}{*}{ Decade } & \multicolumn{4}{|c|}{ Exogenous Decline in Costs, 550 ppm Target } \\
\hline & Elec. & Transp. & Resid. / Com. & Ind. \\
\hline 1990-99 & Oil I / LWR & Oil I & Gas I & Gas I \\
\hline $2000-09$ & Oil I / LWR & Oil I & Gas I & Gas I \\
\hline $2010-19$ & Oil I / LWR & Oil I & Gas I & Gas I \\
\hline $2020-29$ & Oil-Coal. I / LWR & Oil I & Gas I & Gas I \\
\hline 2030-39 & Coal I / LWR & Oil I / LWR & Gas I & Gas I \\
\hline $2040-49$ & Coal I & Oil I/ LWR/ Sol. & Gas I & Gas I / Oil I \\
\hline $2050-59$ & Coal I & Sol. / LWR-FBR & Gas II & Oil I / Gas II \\
\hline $2060-69$ & Solar & Sol. / LWR-FBR & Gas II & Gas II \\
\hline $2070-79$ & Solar & Sol. / LWR-FBR & Gas II & Gas II / Oil II \\
\hline $2080-89$ & Solar & Sol. / LWR-FBR & Gas II & Oil II \\
\hline 2090-99 & Solar & Sol. / LWR-FBR & Gas II & Oil II \\
\hline 2100-09 & Solar & FBR / Solar & Gas II & Oil II / Sol. \\
\hline 2110-19 & Solar & Solar & Gas II & Solar \\
\hline $2120-29$ & Solar & Solar & Gas II /Sol. & Solar \\
\hline $2130-39$ & Solar & Solar & Solar & Oil II / Sol. \\
\hline $2140-49$ & Solar & Solar & Solar & Oil II / Sol. \\
\hline $2150-59$ & Solar & Solar & Solar & Oil II / Sol. \\
\hline $2160-69$ & Solar & Solar & Solar & Oil II / Sol. \\
\hline $2170-79$ & Solar & Solar & Solar & Oil II / Sol. \\
\hline $2180-89$ & Solar & Solar & Solar & Solar \\
\hline$\cdots$ & $\ldots$ & $\ldots$ & $\ldots$ & $\ldots$ \\
\hline
\end{tabular}




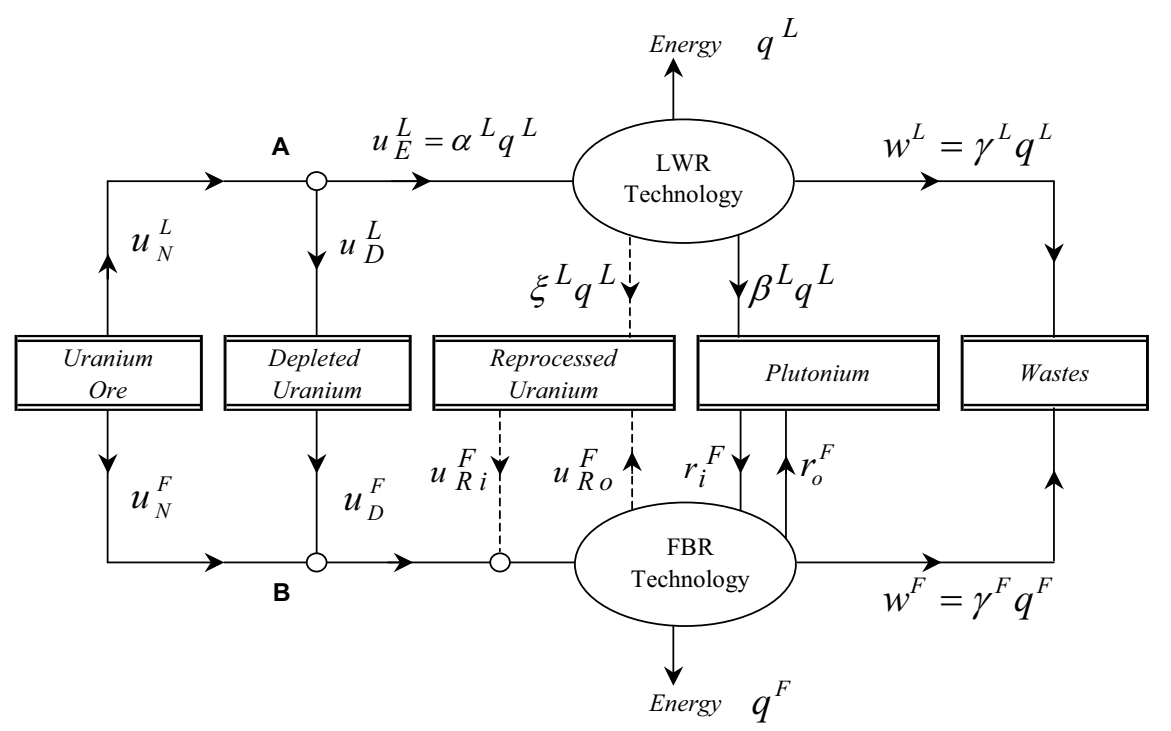

Fig. A1: Flow of Materials in the Nuclear Technology

Table B1. Initial Stocks of Nuclear Fuel and Waste Products ${ }^{1}$

\begin{tabular}{lc}
\hline \hline & Initial Stock \\
\hline Natural uranium $U_{N}(0)$ & 15.4 \\
Depleted uranium $U_{D}(0)$ & 0.917 \\
Reprocessed uranium $U_{R}(0)$ & 0 \\
Plutonium $P u(0)$ & 0.001 \\
Waste Products $W(0)$ & 0.1 \\
\hline \hline
\end{tabular}

(1) in million tons.

Table B2. Technical Coefficients for the Nuclear Technology ${ }^{1}$

\begin{tabular}{lcc}
\hline \hline Parameter & $L W R$ & $F B R$ \\
\hline Enriched uranium & $5.17140 \mathrm{E}-5$ & - \\
Natural, depleted or reprocessed & - & $3.91327 \mathrm{E}-4$ \\
Uranium output (to be reprocessed) & $4.75083 \mathrm{E}-4$ & $3.47851 \mathrm{E}-4$ \\
Plutonium & $6.73894 \mathrm{E}-6$ & $5.0171 \mathrm{E}-6$ \\
Wastes & $3.53062 \mathrm{E}-5$ & $3.34472 \mathrm{E}-5$ \\
\hline \hline
\end{tabular}

(1) in $\mathrm{kg} / \mathrm{mmBTU}$ (the negative exponents reflect the very high energy content in each $\mathrm{kg}$ of fissile material). 
Table B3. Unit Costs for the Nuclear Technology ${ }^{1}$

\begin{tabular}{lcc}
\hline \hline Cost parameters & $L W R$ & $F B R$ \\
\hline Extraction $m m$ & 60 & 60 \\
Enrichment $m^{S}$ & 76 & - \\
Fuel Fabrication $m_{f}^{L}, m_{f}^{F}$, & 305 & 2,600 \\
Operating $v^{L}, v^{F}$ & 5.614 & 8.421 \\
Eprocessing $m_{R}^{L}, m_{R}^{F}$ & 500 & 2,000 \\
Depleted Uranium Storage $s_{U_{D}}$ & 3.5 & - \\
Reprocessed Uranium Storage $s_{U_{R}}$ & 3.6 & 3.6 \\
Plutonium Storage $s_{P u}$ & 1,000 & 1,000 \\
Waste Disposal $s_{W}$ & 400 & 400 \\
\hline$\overline{(1)}$ in $\$ / \mathrm{kg}$ & &
\end{tabular}

Table B4. Sectoral Demand Parameters

\begin{tabular}{lccc}
\hline \hline Sector $i$ & $\begin{array}{c}\text { Constant } \\
\text { parameter }\end{array}$ & $\begin{array}{c}\text { Price } \\
\text { elasticity }\end{array}$ & $\begin{array}{c}\text { Income } \\
\alpha_{j}\end{array}$ \\
elasticity & $\beta_{j}$ \\
\hline 1. Electricity & 0.015927 & -0.65 & 0.92 \\
2. Transportation & 1.699235 & -1.28 & 0.81 \\
3. Residential / Commercial & 0.006730 & $-0,79$ & 1.08 \\
4. Industry & 0.091866 & -0.52 & 0.76 \\
\hline \hline
\end{tabular}

Table B5. Resources Stocks ${ }^{1}$ and Extraction Plus Conversion Costs by Sector (\$/mmBtu)

\begin{tabular}{lcccccc}
\hline \hline & Elec & Transp & Resid & Ind & $\begin{array}{c}\text { Extraction } \\
\text { Costs }^{2}\end{array}$ & Stocks \\
\hline Oil Grade I & 13.21 & 68.65 & 15.81 & 5.28 & 0.60 & $2,100.91$ \\
Oil Grade II & 18.34 & 74.05 & 17.84 & 7.60 & 3.47 & $3,851.67$ \\
Natural gas Grade I & 12.88 & 78.15 & 9.48 & 4,63 & 0.92 & $14,218.50$ \\
Natural gas Grade II & 16.31 & 81.49 & 10.73 & 6.06 & 2.76 & $35,072.30$ \\
Coal Grade I & 15.59 & 113.34 & 21.71 & 11.10 & 1.51 & 989.79 \\
Coal Grade II & 18.85 & 117.22 & 23.10 & 12.49 & 2.37 & $5,802.25$ \\
Coal Grade III & 27.93 & 128.06 & 26.97 & 16.36 & 5.08 & $4,369.58$ \\
Solar & 73.20 & 213.07 & 96.55 & 87.71 & & - \\
Electricity & - & 126.95 & 10.43 & 1.59 & & - \\
\hline \hline
\end{tabular}

(1) The stock of oil, coal and gas are in billion barrels, tons and billion mmBtu, respectively.

(2) in $\$ / m m B t u$.

(3) These are conversion costs of electricity to each sector. For example, the total cost of nuclear

In residential is the cost of nuclear electricity plus the conversion cost of electricity to residential energy. 


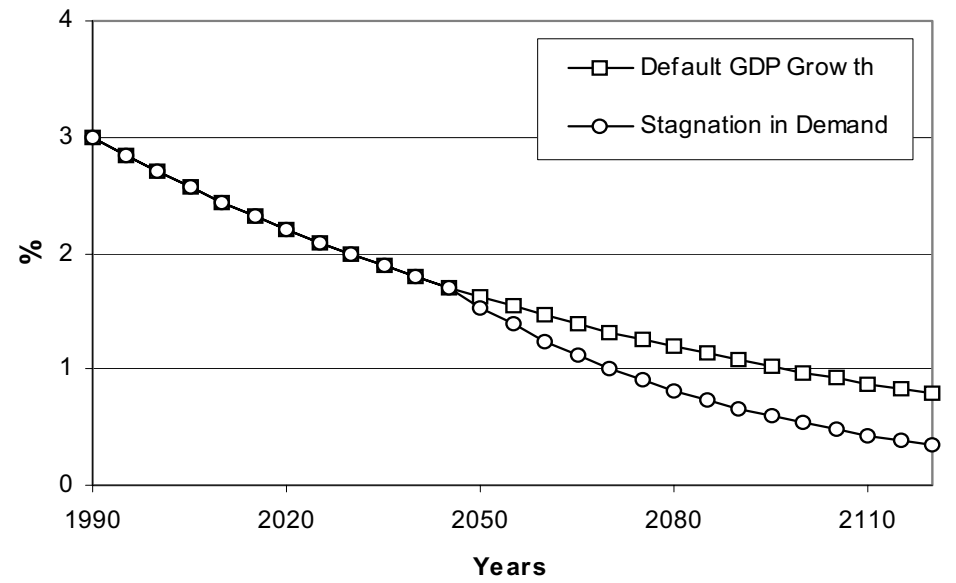

Fig. B1: GDP Growth Rate Assumptions

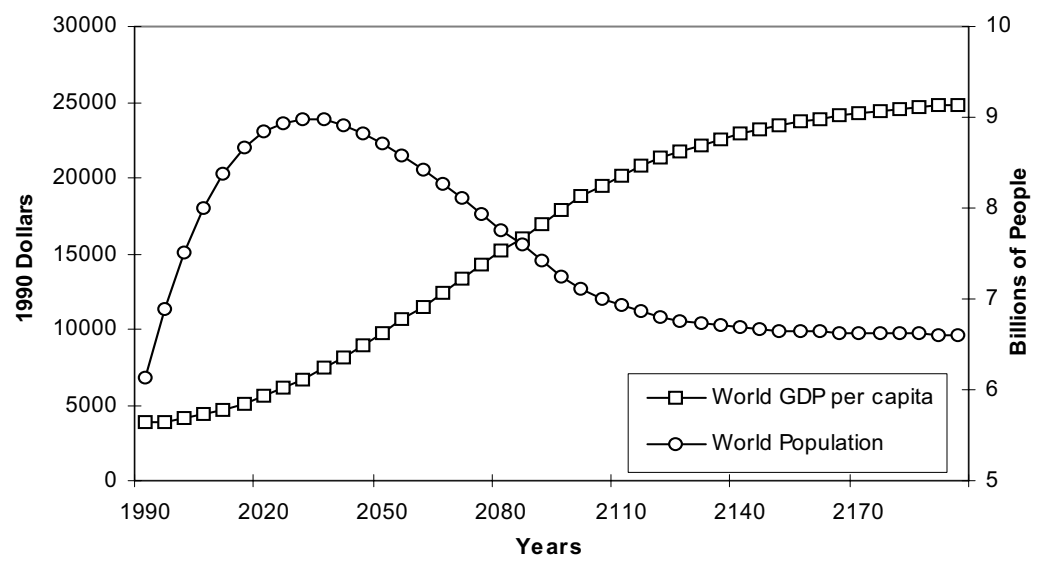

Fig. B2: Stagnation in Demand Growth: GDP per capita and Population Assumptions 